\title{
Development of a Quantitative Instrument to Measure Mobile Collaborative Learning (MCL) Using WhatsApp: The Conceptual Steps
}

\author{
Bangisisi Zamuxolo Mathews Nyembe and Grant Royd Howard ${ }^{(\bowtie)}(\mathbb{D}$ \\ University of South Africa (Unisa), Florida, South Africa \\ 54830222@mylife.unisa.ac.za, howargr@unisa.ac.za
}

\begin{abstract}
It has been reported that WhatsApp, a social media application, had approximately 1.6 billion active users globally as of July 2019, almost one-fifth of the total world's population. Thus, research about WhatsApp's influence in general and especially its influence in education was relevant and significant. While there was much research involving WhatsApp and learning, it was not conclusive about the effects of WhatsApp on student learning. Specifically, research focusing on collaborative learning using WhatsApp was lacking, including research instruments for measuring collaboration on WhatsApp. Consequently, the paper's research problem was the lack of research instruments for measuring collaboration on WhatsApp in relation to academic achievement. To address the research problem, the study followed the important initial and conceptual steps of the instrument development process to develop a research instrument to measure collaboration on WhatsApp in relation to academic achievement. The result of the paper was a developed instrument that provides researchers with a basis to measure the explanatory constructs involved in mobile collaborative learning (MCL) processes on WhatsApp and potentially other social media platforms. Therefore, the paper made an appropriately theoretical contribution, which was grounded in the scientific literature. The study facilitated positivistic research and epistemology for acquiring objective and precise scientific knowledge. Such deductive research promotes theory testing and development and presents educators and students with scientific evidence about learning with MCL applications such as WhatsApp from which both curriculum and learning design can be informed and benefited. In the age of connected mobility this is a necessity.
\end{abstract}

Keywords: Information Systems (IS) · Information Technology (IT) • Mobile collaborative learning (MCL) $\cdot$ Mobile learning (M-learning) $\cdot$ Quantitative instrument development $\cdot$ Social media $\cdot$ WhatsApp

\section{Introduction}

Mobile digital technologies and social media continue to pervade many facets of our daily lives and enable communication, collaboration and content creation. Within the broad scope of mobile digital technologies and social media, the social media 
application called 'WhatsApp' has become particularly prevalent. WhatsApp is technically an internet-based cross-platform instant messaging and voice over Internet Protocol (VoIP) service for mobile devices [1].

As of July 2019, it was reported that WhatsApp had approximately 1.6 billion active users globally [2], which is almost one-fifth of the total world's population at that time. In the context of other popular worldwide social media applications, WhatsApp is placed behind Facebook and YouTube only as the most popular social media application. WhatsApp's user base is significant, which warrants scientific evidence of its effects in our lives.

WhatsApp's user base includes students and while there is active research involving WhatsApp and learning, the research is not conclusive about the effects of WhatsApp on student learning. For example, one study reported that WhatsApp improved learning [7] and another reported that WhatsApp did not [8]. Furthermore, in a recent study, the reviewed literature showed research about WhatsApp and teaching and learning from various viewpoints, but none measured collaboration on WhatsApp in relation to academic achievement [9], including there being a lack of instruments for measuring collaboration on WhatsApp. This was the research problem.

Subsequently, the research question was what constructs and instrument were appropriate for measuring collaboration on WhatsApp in relation to academic achievement? The research objective was to develop a quantitative instrument to answer the research question. The study focused on the important conceptual steps of the instrument development process rather than the empirical steps. Thus, the study made an appropriately theoretical contribution, which was grounded in the scientific literature.

Answering the research question has significant value for researchers in the domain. It allows them the quantify the effects of collaboration on social media and similar applications in relation to academic achievement and it facilitates theory development. This provides significant value to educators and students about how to incorporate social media, mobile collaborative learning (MCL) and WhatsApp into their teaching and learning. The paper facilitates a positivistic epistemology based on the scientific method for objectivity and precision. Hence, the study provides an original contribution to the scientific body of knowledge in the broad domains of MCL and m-learning. Furthermore, the study contributes to knowledge generation in Africa, since less than a fifth of the articles reviewed related to studies in Africa [9].

The paper consists of four sections. The first section introduced the study's context and explained the research problem, question and objective. The next section reviewed m-learning and WhatsApp and learning. Section 3 provided the instrument development process, which enabled the study to answer the research question. Section 4 concludes the paper and explains its contribution, limitations and opportunities for future research. 


\section{Literature Review}

\subsection{Mobile Learning (M-learning)}

Mobile and social media technologies are a relatively recent development, but human learning is a natural human process and many theories to explain how human learning occurs have been developed since the time of the Ancient Greek philosophers [9]. However, Collaborative Learning, Communities of Practice, Connectivism, Conversation Theory and Social Learning Theory appear to relate especially well to learning with mobile and social media technologies. Nevertheless, researchers continued with a new learning theory to explain specifically learning with mobile technologies, namely M-learning Theory [10].

M-learning Theory has attracted the attention of many researchers who acknowledge the potential of applying mobile and social media technologies to improve learning $[11,12]$. M-learning Theory does not replace traditional learning theories; instead it complements them by emphasizing the mobility of learning, including how learning is acquired across various contexts, while on the move and across the transitions of life. M-learning Theory also takes into consideration learning that happens at home, work, outdoors, places of leisure, places of worship, cafes, stores and while travelling. M-learning Theory continues to be researched, defined and evolved together with the evolution of mobile hardware, software and social media technologies.

Three key aspects of M-learning Theory have been identified, namely personalization, authenticity and collaboration, which occur outside of the traditional learning time and space constraints [13]. Personalization is based in Socio-cultural Theory and Motivational Theory and involves learner choice, agency, self-regulation and customization. Authenticity refers to the real-world relevance, practices and personal meaning in everyday life situations. Collaboration involves participating in rich learning interactions with other people, which is the m-learning aspect that the study focused on together with the social media application called 'WhatsApp'.

\subsection{WhatsApp and Learning}

WhatsApp has evolved into a promising educational tool that has the potential to promote interaction and participation during student learning activities [14-17]. WhatsApp enables anonymous, asynchronous collaborative learning, which is reported to improve and increase the productivity and participation of less confident learners [18]. WhatsApp helps to create immediacy and connection in informal learning, formal blended learning, open distance learning and learning outside of the classroom [15, 19].

However, despite the documented benefits, challenges have been reported, including extra workload, distraction from learning, less commitment to participate, exposure to unregulated messages, false information, addictive behavior and increased expenses $[17,20]$. In addition, WhatsApp use may result in stress, lack of privacy and difficulties managing responsibilities, especially for more mature students [15]. Married students have also found WhatsApp disruptive because its use collided with their family time [18]. In contrast, there is research indicating that students have found 
learning on WhatsApp interesting, convenient and motivating [21]. It can be argued that WhatsApp is affordable to use and increases the chances of learners participating in learning activities [22].

Several learning theories have been applied in WhatsApp studies. Socio-cultural Theory was involved in a study where WhatsApp was used for learning English as a second language [16]. Activity Theory was used to analyze learner interactions on WhatsApp for improving critique writing skills of English as a foreign language [23] and in a WhatsApp study to identify factors that influence students' participation in mobile learning activities and online discussions [19]. Activity Theory, Situated Learning Theory and Communities of Practice were applied in a study to understand how WhatsApp could support teaching and learning in higher education [15]. Experiential Learning Theory was applied in a study where WhatsApp was used to improve the standard of primary health care education [24]. Thus, several of the prominent learning theories have been applied in various ways to study WhatsApp. However, the important concept of collaboration had not been explicitly measured to expose its effect on learning anywhere and anytime with WhatsApp.

\section{Instrument Development}

\subsection{MacKenzie et al.'s (2011) Framework}

MacKenzie et al.'s (2011) framework for instrument development was used to guide the development of the quantitative instrument for measuring collaboration using WhatsApp [25]. This framework was selected because it was published in an extensive study updating important prior research on Information Systems (IS) instrument development and published in arguably the top journal in the IS field, namely MIS Quarterly. In addition, it is a fairly recent publication and has been cited by 1793 according to Google Scholar as of 22 December 2019. The framework provides a 10step procedure for instrument development starting with construct conceptualization or reconceptualization and ending in the development of norms [26]. Nonetheless, since the scope of the study was limited to the important conceptual steps only, the first four conceptual steps of the framework were applied.

\subsection{Step 1: Conceptualization}

Constructs are abstract concepts developed for research or scientific purposes [25]. Construct conceptualization involves defining the conceptual domain of each construct. Each construct should be defined unambiguously and consistently with prior research. Thus, instruments that related to the measurement of collaboration from various fields were reviewed and evaluated based on their appropriateness and construct validity and reliability measures [27, 28]. Only those that had applicability, established construct validity and high reliability measures were included as inputs into the instrument development process.

The instruments were the Thomson, Perry and Miller Collaboration Instrument [29], the Thomson, Perry and Miller (2007) Collaboration Instrument in the South 
African Context [30], the Collaboration with Medical Staff Scale of the Nurses Opinion Questionnaire (CMSS-NOQ) [31], the Collaboration and Trust in an Education Context [32], the Wilder Collaboration Factors Inventory [33], the Collaboration Index [34], the Collaborative Culture Scale [35], the Assessment of Inter-professional Team Collaboration Scale [36], the Collaboration Assessment Tool (CAT) [37], the Transdisciplinary Tobacco Use Research Centers (TTURC) Researcher Survey [38], the Index of Interprofessional Team Collaboration for Expanded School Mental Health (IITCESMH) [39], the Teacher Collaboration Assessment Survey (TCAS) [40], the Distance Education Learning Environment Survey (DELES) [41], the Index of Interdisciplinary Collaboration (IIC) [42], the Expanded School Mental Health Collaboration Instrument [School Version] [43] and the Collaborative Practice Assessment Tool (CPAT) [44].

For each instrument, all its specified factors/constructs were evaluated by the authors. The evaluation was directed by importance to the research problem and parsimony. The selected and adapted constructs were Interaction (IA), Support (S), Information Exchange (IE), Sense of Community (SC), Interdependence (ID), Trust $(\mathrm{T})$, Active Learning (AL), Formality $(\mathrm{F})$ and Collaboration (C). In addition, the construct Academic Achievement (AA) was included since it was essential for addressing the research problem. All the constructs would apply to students/learners who use WhatsApp for academic learning.

Interaction (IA) was defined as the amount of reciprocal action and engagement, such as discussing, sharing, chatting and meeting, between two or more learners using WhatsApp for academic learning. Support (S) was defined as the amount of help and assistance that is provided to a learner, who is experiencing learning difficulties, by other learners using WhatsApp for academic learning. Information Exchange (IE) was defined as the amount of information exchanged as part of the learning processes using WhatsApp for academic learning. Sense of Community (SC) was defined as a learner's feeling of belonging to a group with shared interests, goals and needs, using WhatsApp for academic learning. Interdependence (ID) was defined as the contingency or condition that other learners are part of a learner's learning process, using WhatsApp for academic learning. Trust (T) was defined as the level of confidence that a learner has in other learners using WhatsApp for academic learning. Active Learning (AL) was defined as being opposite to passive learning and comprises meaningful learning activities and applied learning on WhatsApp for academic learning. Formality (F) was defined as how casual and relaxed or academically correct and serious the engagement is between a learner and the other learners by virtue of the language they use, using WhatsApp for academic learning. Collaboration (C) was defined as the amount of working and contributing together that takes place in a group of learners to achieve the common goal of learning using WhatsApp.

In addition, it is necessary to measure a student's academic achievement in an acceptable way to address the research problem. Actual student grades are variables that measure academic achievement. However, the eventual instrument users may not have access to respondents' grades, thus, a construct called Academic Achievement (AA) was defined as a learner's self-reported academic achievement. 


\subsection{Step 2: Generate Items to Represent the Constructs}

Following the conceptual definitions of the selected constructs, a set of items to represent the conceptual domain of each construct was generated [25]. The items generated were adapted from the instruments reviewed and are provided in Table 1. Six items per construct were generated to balance adequate domain sampling and parsimony for construct and content validity and response bias and fatigue [45]. Each item is measured using a five-point Likert measurement scale from 1 to 5 , where $1=$ "strongly disagree", 2 = "disagree", 3 = "neither disagree nor agree", 4 = "agree" and $5=$ "strongly agree" [46]. The higher the aggregate value for each item the more of that construct is evident on WhatsApp for academic learning.

In addition to the items in Table 1, a participant would be asked several initial questions that would provide useful information and analyses about their characteristics. These questions include gender, home language, age range, study major, study qualification level, year level of qualification, do you use WhatsApp with other students for learning (if you mark "No", then please indicate your reasons for not using WhatsApp for learning and then there are no further questions for you to answer, thank you for participating)? How many hours do you estimate that you spend on WhatsApp every week with other students for learning? What devices do you use when learning with other students on WhatsApp? Where, what places, do you use WhatsApp for learning with other students? Is there anything that prevents you from using WhatsApp more often or in more places for learning with other students?

Table 1. Measurement items for each construct.

\begin{tabular}{|c|c|c|}
\hline \# & Construct & Measurement items \\
\hline \multirow[t]{7}{*}{1} & \multirow[t]{7}{*}{ Interaction (IA) } & When I am on WhatsApp with other students: \\
\hline & & 1. We have discussions to learn from each other \\
\hline & & 2. We participate with each other to learn \\
\hline & & 3. We have chats to learn from each other \\
\hline & & 4. We share with each other to learn \\
\hline & & 5. We have meetings with each other to learn \\
\hline & & 6. We communicate with each other to learn \\
\hline \multirow[t]{7}{*}{2} & \multirow[t]{7}{*}{ Support (S) } & When I am on WhatsApp with other students: \\
\hline & & 1. They help me on my courses/modules \\
\hline & & 2. They reduce the stress from my courses/modules \\
\hline & & 3. They assist with difficult parts of my courses/modules \\
\hline & & 4. They aid me when I am stuck on my courses/modules \\
\hline & & 5. They lend a hand so I can figure out my courses/modules \\
\hline & & $\begin{array}{l}\text { 6. They encourage me to keep going on my } \\
\text { courses/modules }\end{array}$ \\
\hline
\end{tabular}


Table 1. (continued)

\begin{tabular}{|c|c|c|}
\hline \# & Construct & Measurement items \\
\hline \multirow[t]{7}{*}{3} & \multirow{7}{*}{$\begin{array}{l}\text { Information Exchange } \\
\text { (IE) }\end{array}$} & When I am on WhatsApp with other students: \\
\hline & & 1. We send and receive course/module information \\
\hline & & 2. Course/module material gets passed around \\
\hline & & 3. We swap course/module information \\
\hline & & 4. Course/module material is spread around \\
\hline & & 5. We distribute course/module information \\
\hline & & 6. Course/module knowledge is circulated \\
\hline \multirow[t]{7}{*}{4} & \multirow{7}{*}{$\begin{array}{l}\text { Sense of Community } \\
\text { (SC) }\end{array}$} & When I am on WhatsApp with other students: \\
\hline & & 1. I feel that I belong to a learning group \\
\hline & & 2. I matter to my learning group \\
\hline & & 3. My learning group matters to me \\
\hline & & 4. My learning group benefits our learning \\
\hline & & 5. My learning group has shared interests in learning \\
\hline & & 6. My learning group has similar academic goals \\
\hline \multirow[t]{7}{*}{5} & \multirow[t]{7}{*}{ Interdependence (ID) } & When I am on WhatsApp with other students: \\
\hline & & 1. I rely on other students to learn \\
\hline & & 2. Other students rely on me to learn \\
\hline & & 3. My learning requires other students \\
\hline & & 4. I need other students to learn \\
\hline & & 5. Other students need me to learn \\
\hline & & 6. My learning is conditional on other students \\
\hline \multirow[t]{7}{*}{6} & \multirow[t]{7}{*}{ Trust $(\mathrm{T})$} & When I am on WhatsApp with other students: \\
\hline & & 1. Other students provide honest course/module advice \\
\hline & & $\begin{array}{l}\text { 2. I believe in what other students say to me about } \\
\text { courses/modules }\end{array}$ \\
\hline & & $\begin{array}{l}\text { 3. I have faith in the course/module communication from } \\
\text { other students }\end{array}$ \\
\hline & & $\begin{array}{l}\text { 4. The course/module discussions with other students are } \\
\text { sincere }\end{array}$ \\
\hline & & $\begin{array}{l}\text { 5. The course/module conversations with other students are } \\
\text { genuine }\end{array}$ \\
\hline & & $\begin{array}{l}\text { 6. I am certain that other students provide truthful } \\
\text { information }\end{array}$ \\
\hline \multirow[t]{7}{*}{7} & \multirow[t]{7}{*}{ Active Learning (AL) } & When I am on WhatsApp with other students: \\
\hline & & 1. I learn by having debates with other students \\
\hline & & 2. I learn by working on questions with other students \\
\hline & & 3. I learn by doing activities with other students \\
\hline & & 4. I learn by solving study problems with other students \\
\hline & & 5. I teach other students learning material \\
\hline & & $\begin{array}{l}\text { 6. I show other students how to figure out their } \\
\text { courses/modules }\end{array}$ \\
\hline
\end{tabular}


Table 1. (continued)

\begin{tabular}{|c|c|c|}
\hline \# & Construct & Measurement items \\
\hline \multirow[t]{7}{*}{8} & \multirow[t]{7}{*}{ Formality (F) } & When I am on WhatsApp with other students: \\
\hline & & $\begin{array}{l}\text { 1. We use academic language only when talking about } \\
\text { courses/modules }\end{array}$ \\
\hline & & $\begin{array}{l}\text { 2. Messages about courses/modules contain academic } \\
\text { content only }\end{array}$ \\
\hline & & 3. When learning, we use correct wording only \\
\hline & & 4. When learning, we discuss academic content only \\
\hline & & $\begin{array}{l}\text { 5. During course/module communication, we use scientific } \\
\text { language only }\end{array}$ \\
\hline & & $\begin{array}{l}\text { 6. We use textbook wording only when chatting about } \\
\text { courses/modules }\end{array}$ \\
\hline \multirow[t]{7}{*}{9} & \multirow[t]{7}{*}{ Collaboration $(\mathrm{C})$} & When I am on WhatsApp with other students: \\
\hline & & 1. We work together to understand our courses/modules \\
\hline & & 2. We learn collectively to solve course/module problems \\
\hline & & 3. We contribute jointly to learn our courses/modules \\
\hline & & 4. When preparing for tests or exams we learn together \\
\hline & & 5. We study as a group \\
\hline & & 6. We learn our courses/modules together \\
\hline \multirow[t]{7}{*}{10} & \multirow{7}{*}{$\begin{array}{l}\text { Academic Achievement } \\
\text { (AA) }\end{array}$} & Since I started using WhatsApp for learning: \\
\hline & & 1. My courses'/modules' marks have improved \\
\hline & & 2. I do better in tests and exams \\
\hline & & 3. I am able to achieve better success in my assignments \\
\hline & & 4. I have had more success in my courses/modules \\
\hline & & 5. I understand my courses/modules better \\
\hline & & 6. My courses/modules are easier to do \\
\hline
\end{tabular}

\subsection{Step 3: Assess the Content Validity of the Items}

After the items were generated for each construct, they were assessed for their content validity, which relates to how well a construct's items represent all aspects of that construct [25]. Raters are recommended for doing this assessment and university educated students are considered adequately representative of the intended generalized population [25]. Given the conceptual focus of the study, the study's supervisor performed the initial item generation and adaptation and the study's second researcher, a postgraduate university educated student conducted the assessment. Although it is recommended to use one-way repeated measures ANOVA to determine if an item's mean rating on one construct differs from its ratings on the other constructs, it requires more than two raters [47], so instead a qualitative assessment was conducted by the second researcher. The second researcher was requested, for each item, to assess whether the item represented the content of the construct that it was assigned to measure, and for each construct, whether all the items assigned to measure that construct represented the entire content of that construct. After three iterations and changes, the final items are presented in Table 1. 


\subsection{Step 4: Formally Specify the Measurement Model}

Step 4 involves specifying the measurement model, including how the items relate to the constructs. Figure 1 provides the initial measurement model which depicts all constructs with reflective indicators. The paper specifies all of the constructs as unidimensional or reflective constructs and there are no sub-dimensions or conceptually distinguishable facets [48].

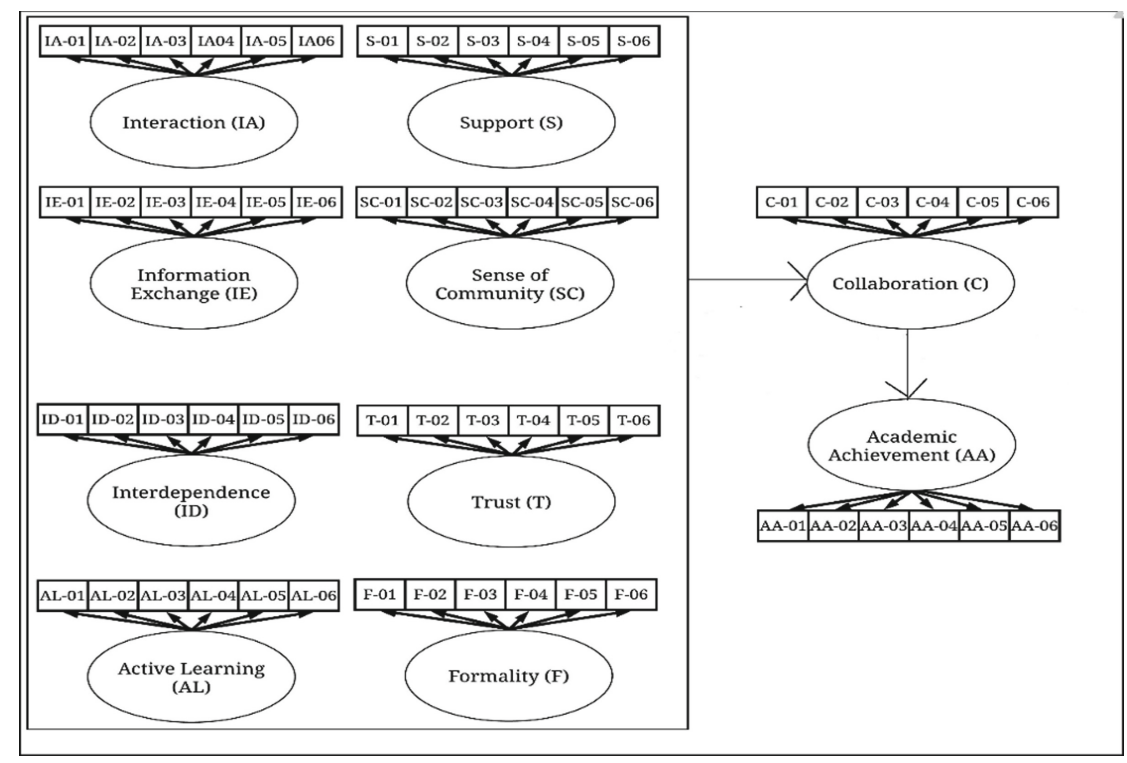

Fig. 1. Initial measurement model for the study.

At this conceptual stage it is not known how each of the constructs IA, S, IE, SC, ID, T, AL and F interrelate. However, based on the reviewed instruments and literature it is evident that they are important when measuring and influence C. Thus, only a general relationship is specified between all those constructs and $\mathrm{C}$. Also, the relationship from $\mathrm{C}$ to AA is specified since it is the central focus of the study. These relationships can be specified as the following alternate hypotheses (HA1-n): IA positively influences $\mathrm{C}, \mathrm{S}$ positively influences $\mathrm{C}$, IE positively influences $\mathrm{C}$, SC positively influences $C$, ID positively influences $C, T$ positively influences $C, A L$ positively influences $\mathrm{C}, \mathrm{F}$ negatively or positively influences $\mathrm{C}$ and $\mathrm{C}$ positively influences AA. The corresponding null hypotheses (H01-n) specify that there are no associations among each set of constructs. 


\section{Conclusion}

The study has addressed the research problem, being the lack of research instruments measuring collaboration on WhatsApp in relation to academic achievement, by completing the conceptual steps to develop an appropriate measurement instrument. The developed measurement instrument answers the research question by demonstrating appropriate constructs and an instrument for measuring collaboration on WhatsApp in relation to academic achievement. This provides an original contribution to the scientific literature.

The instrument provides researchers with a foundation from which to measure informative constructs involved in the mobile collaborative learning (MCL) processes on WhatsApp and potentially other mobile and social media platforms. The study facilitates positivistic research and epistemology to further the objectives of acquiring objective and precise scientific knowledge. Such deductive research promotes theory testing and development.

MCL theory testing and development provides educators and students with scientific evidence about learning with MCL applications such as WhatsApp, from which both curriculum and learning design can be informed and benefited. In the age of connected mobility this is a necessity.

Limitations include the lack of empirical data for testing the psychometric properties of the instrument and the relationships among the constructs in actual learning environments. These limitations provide valuable research opportunities involving instrument pilot tests, scale purification and refinement and even norms development. In addition, the instrument could be adapted for various other MCL supported mobile and social media applications for further knowledge development.

\section{References}

1. WhatsApp: WhatsApp.com. https://www.whatsapp.com. Accessed 04 Nov 2019

2. Statista.com: Global-social-networks-ranked-by-number-of-users. https://www.statista.com/ statistics/272014/global-social-networks-ranked-by-number-of-users/. Accessed 4 Nov 2019

3. Gikas, J., Grant, M.M.: Mobile computing devices in higher education: student perspectives on learning with cellphones, smartphones \& social media. Internet High. Educ. 19, 18-26 (2013). https://doi.org/10.1016/j.iheduc.2013.06.002

4. Jeng, Y.-L., Wu, T.-T., Huang, Y.-M., Tan, Q., Yang, S.J.H.: The add-on impact of mobile applications in learning strategies: a review study. J. Educ. Technol. Soc. 13, 3-11 (2010). https://www.jstor.org/stable/jeductechsoci.13.3.3

5. Garcia-Cabot, A., De-Marcos, L., Garcia-Lopez, E.: An empirical study on m-learning adaptation: learning performance and learning contexts. Comput. Educ. 82, 450-459 (2015). https://doi.org/10.1016/j.compedu.2014.12.007

6. Caballé, S., Xhafa, F., Barolli, L.: Using mobile devices to support online collaborative learning. Mob. Inf. Syst. 6, 27-47 (2010). http://dx.doi.org/10.3233/MIS-2010-0091

7. Pimmer, C., Brühlmann, F., Odetola, T.D., Oluwasola, D.O., Dipeolu, O., Ajuwon, A.J.: Facilitating professional mobile learning communities with instant messaging. Comput. Educ. 128, 102-112 (2019). https://doi.org/10.1016/j.compedu.2018.09.005 
8. Alkhalaf, A.M., Tekian, A., Park, Y.S.: The impact of WhatsApp use on academic achievement among Saudi medical students. Med. Teach. 40, S10-S14 (2018). https://doi. org/10.1080/0142159X.2018.1464652

9. Nyembe, B.Z.M., Howard, G.R.: The utilities of prominent learning theories for mobile collaborative learning (MCL) with reference to WhatsApp and m-learning. In: Maharaj, M., Singh, U.G. (eds.) The 2nd International Conference on Advances in Big Data, Computing and Data Communication Systems (icABCD), Winterton, South Africa, pp. 227-232. IEEE (2019). https://doi.org/10.1109/ICABCD.2019.8851042

10. Parsons, D.: A mobile learning overview by timeline and mind map. Int. J. Mob. Blended Learn. 6, 1-21 (2014). https://doi.org/10.4018/ijmbl.2014100101

11. Sharples, M., Taylor, J., Vavoula, G.: Towards a theory of mobile learning. In: The 4th World Conference on Mobile Learning (mLearn 2005), Cape Town, South Africa, pp. 1-9 (2005)

12. Vavoula, G., Sharples, M.: Meeting the challenges in evaluating mobile learning: a 3-level evaluation framework. Int. J. Mob. Blended Learn. 1, 54-75 (2009). https://doi.org/10.4018/ jmbl.2009040104

13. Kearney, M., Schuck, S., Burden, K., Aubusson, P.: Viewing mobile learning from a pedagogical perspective. Res. Learn. Technol. 20, 1-17 (2012). https://doi.org/10.3402/rlt. v20i0.14406

14. Bouhnik, D., Deshen, M.: WhatsApp goes to school: mobile instant messaging between teachers and students. J. Inf. Technol. Educ. 13, 217-231 (2014). https://0-doi-org.oasis. unisa.ac.za/10.28945/2051

15. Gachago, D., Strydom, S., Hanekom, P., Simons, S., Walters, S.: Crossing boundaries: lectures' perspectives on the use of WhatsApp to support teaching and learning in higher education. Progressio 37, 172-187 (2015). https://0-hdl-handle-net.oasis.unisa.ac.za/10520/ EJC180393

16. Andujar, A.: Benefits of mobile instant messaging to develop ESL writing. System 62, 6376 (2016). https://0-doi-org.oasis.unisa.ac.za/10.1016/j.system.2016.07.004

17. Aburezeq, I.M., Ishtaiwa, F.F.: The impact of WhatsApp on interaction in an Arabic language teaching course. Int. J. Arts Sci. 6, 165-180 (2013). https://0-search-proquest-com. oasis.unisa.ac.za/docview/1496695544?accountid=14648

18. Rambe, P., Bere, A.: Using mobile instant messaging to leverage learner participation and transform pedagogy at a South African University of Technology. Br. J. Educ. Technol. 44, 544-561 (2013). https://doi.org/10.1111/bjet.12057

19. Barhoumi, C.: The effectiveness of WhatsApp mobile learning activities guided by activity theory on students' knowledge management. Contemp. Educ. Technol. 6, 221-238 (2015). https://search.proquest.com/docview/2135157613?accountid=14648

20. Ahad, A.D., Lim, S.M.A.: Convenience or nuisance?: The 'WhatsApp' dilemma. Procedia Soc. Behav. Sci. 155, 189-196 (2014). https://0-doi-org.oasis.unisa.ac.za/10.1016/j.sbspro. 2014.10.278

21. So, S.: Mobile instant messaging support for teaching and learning in higher education. Internet High. Educ. 31, 32-42 (2016). https://0-doi-org.oasis.unisa.ac.za/10.1016/j.iheduc. 2016.06.001

22. Bere, A., Rambe, P.: An empirical analysis of the determinants of mobile instant messaging appropriation in university learning. J. Comput. High. Educ. 28, 172-198 (2016). https://0doi-org.oasis.unisa.ac.za/10.1007/s12528-016-9112-2

23. Awada, G.: Effect of WhatsApp on critique writing proficiency and perceptions toward learning. Cogent. Educ. 3, 1-25 (2016). https://doi.org/10.1080/2331186X.2016.1264173 
24. Willemse, J.J.: Undergraduate nurses reflections on Whatsapp use in improving primary health care education. Curationis 38, 1-7 (2015). https://doi.org/10.4102/curationis.v38i2. 1512

25. MacKenzie, S.B., Podsakoff, P.M., Podsakoff, N.P.: Construct measurement and validation procedures in MIS and behavioral research: integrating new and existing techniques. MIS Q. 35, 293-334 (2011). https://doi.org/10.2307/23044045

26. Hoehle, H., Venkatesh, V.: Mobile application usability: conceptualization and instrument development. MIS Q. 39, 435-472 (2015). https://pdfs.semanticscholar.org/8171/ 405b2c1538c6b2eff0eb7fb87b7b2c68eeba.pdf

27. Ariola, M.M.: Principles and Methods of Research. Rex Book Store Inc., Manilla (2006)

28. Straub, D.W.: Validating instruments in MIS research. MIS Q. 13, 147-169 (1989). https:// doi.org/10.2307/248922

29. Thomson, A.M., Perry, J.L., Miller, T.K.: Conceptualizing and measuring collaboration. J. Public Adm. Res. Theory. 19, 23-56 (2009). https://0-doi-org.oasis.unisa.ac.za/10.1093/ jopart/mum036

30. Roberts, D., Van Wyk, R., Dhanpat, N.: Validation of the Thomson, Perry and Miller (2007) collaboration instrument in the South African context. SA J. Hum. Resour. Manag. 15, 1-11 (2017). https://dx.doi.org/10.4102/sajhrm.v15i0.793

31. Dougherty, M.B., Larson, E.: A review of instruments measuring nurse-physician collaboration. JONA J. Nurs. Adm. 35, 244-253 (2005). https://journals.lww.com/jona journal/Abstract/2005/05000/A_Review_of_Instruments_Measuring_Nurse_Physician.8. aspx

32. Hoy, W.K., Tschannen-Moran, M.: Five faces of trust: an empirical confirmation in urban elementary schools. J. Sch. Leadersh. 9, 184-208 (1999). https://doi.org/10.1177/10526846 9900900301

33. Townsend, A., Shelley, K.: Validating an instrument for assessing workforce collaboration. Community Coll. J. Res. Pract. 32, 101-112 (2008). https://doi.org/10.1080/1066892070 1707813

34. Simatupang, T., Sridharan, R.: The collaboration index: a measure for supply chain collaboration. Int. J. Phys. Distrib. Logist. Manag. 35, 44-62 (2005). https://doi.org/10.1108/ 09600030510577421

35. López, S.P., Peón, J.M.M., Ordás, C.J.V.: Managing knowledge: the link between culture and organizational learning. J. Knowl. Manag. 8, 93-104 (2004). https://0-doi-org.oasis. unisa.ac.za/10.1108/13673270410567657

36. Orchard, C.A., King, G.A., Khalili, H., Bezzina, M.B.: Assessment of interprofessional team collaboration scale (AITCS): development and testing of the instrument. J. Contin. Educ. Health Prof. 32, 58-67 (2012). https://doi.org/10.1002/chp.21123

37. Marek, L., Brock, D., Savla, J.: Evaluating collaboration for effectiveness: conceptualization and measurement. Am. J. Eval. 36, 67-85 (2015). https://doi.org/10.1177/109821401453 1068

38. Mâsse, L.C., et al.: Measuring collaboration and transdisciplinary integration in team science. Am. J. Prev. Med. 35, S151-S160 (2008). https://doi.org/10.1016/j.amepre.2008. 05.020

39. Mellin, E.A., Bronstein, L., Anderson-Butcher, D., Amorose, A.J., Ball, A., Green, J.: Measuring interprofessional team collaboration in expanded school mental health: model refinement and scale development. J. Interprof. Care 24, 514-523 (2010). https://doi.org/10. 3109/13561821003624622

40. Woodland, R., Lee, M.K., Randall, J.: A validation study of the teacher collaboration assessment survey. Educ. Res. Eval. 19, 442-460 (2013). https://doi.org/10.1080/13803611. 2013.795118 
41. Walker, S.L., Fraser, B.J.: Development and validation of an instrument for assessing distance education learning environments in higher education: the Distance Education Learning Environments Survey (DELES). Learn. Environ. Res. 8, 289-308 (2005). https://0doi-org.oasis.unisa.ac.za/10.1007/s10984-005-1568-3

42. Bronstein, L.R.: Index of interdisciplinary collaboration (Instrument Development). Soc. Work Res. 26, 113-127 (2002). https://link.gale.com/apps/doc/A89491142/AONE?u=usa_ itw\&sid=AONE\&xid=0d0d968c

43. Mellin, E.A., Taylor, L., Weist, M.D.: The expanded school mental health collaboration instrument [school version]: development and initial psychometrics. School Ment. Health 6, 151-162 (2014). https://doi.org/10.1007/s12310-013-9112-6

44. Schroder, C., et al.: Development and pilot testing of the collaborative practice assessment tool. J. Interprof. Care 25, 189-195 (2011). https://doi.org/10.3109/13561820.2010.532620

45. Hinkin, T.R.: A review of scale development practices in the study of organizations. J. Manage. 21, 967-988 (1995). https://doi.org/10.1177/014920639502100509

46. Sekaran, U., Bougie, R.: Research Methods for Business: A Skill Building Approach. Wiley, Chichester (2013)

47. Tredoux, C., Durrheim, K. (eds.): Numbers, Hypotheses \& Conclusions: A Course in Statistics for the Social Sciences. UCT Press, Cape Town (2005)

48. Petter, S., Straub, D.W., Rai, A.: Specifying formative constructs in information systems research. MIS Q. 31, 623-656 (2007). https://doi.org/10.2307/25148814 